\title{
Jacques Rancière, cenografias políticas
}

\author{
Jacques Rancière, political scenographies
}

RANCIÈRE, Jacques. La méthode de l'égalité: entretien avec Laurent Jeanpierre et Dork Zabanyan. Paris: Bayard, 2012, 333 p.

\section{Marlon Salomon*}

marlonsalomon@gmail.com

Professor associado

Universidade Federal de Goiás

Faculdade de História, UFG, Campus II, Caixa Postal 131

74001-970 - Goiânia - GO

Brasil

\section{Palavras-chave}

Acontecimento; Filosofia da história; Política.

Keywords

Event; Philosophy of history; Policy.

* Bolsista Produtividade em Pesquisa CNPq 
Desde 2005, conhecíamos em bloco o crítico, o escritor de textos curtos de jornal sobre arte, política, filosofia, o cronista dos tempos consensuais. Nos últimos anos, vimos aparecer na cena intelectual um Jacques Rancière "falante". Não nos referimos ao pequeno A partilha do sensível (2005), livro-entrevista que acreditávamos ser um trabalho à parte entre seus livros. A publicação de Et tant pis pour les gens fatigués. Entretiens (2009) colocou à disposição do público um conjunto extenso e importante de entrevistas concedidas pelo filósofo francês (muitas das quais desconhecidas ou de difícil acesso) ao longo de décadas de trabalho. A publicação dessa coletânea, para além de sua importância particular para aqueles que se interessam pela história do seu pensamento, mostrou o estatuto particular que esse tipo de atividade possui, em geral, em sua filosofia: não se trata de um momento de interrupção de sua reflexão com o intuito de promover ou vulgarizar suas ideias, mas de um momento efetivo de exercício do pensamento - que não se confunde, no entanto, com seu trabalho de pesquisa e de escrita. Não se trata da tagarelice tão comum em nossos dias, de opinião sobre assunto qualquer, cuja solicitação seduz amiúde muitos intelectuais.

Não deixa de ser interessante observar que apenas três anos após essa coletânea, Rancière conceda uma longa entrevista a Laurent Jeanpierre e a Dork Zabunyan, que sai agora em livro sob o título La méthode de l'égalité. Poderíamos falar sobre esse "gênero" literário tipicamente francês, o livro-entrevista com intelectuais, mas o importante aqui é situar seu estatuto na trajetória desse autor que desde os anos 70 vem pensando contra a própria ideia de "gêneros". Se a entrevista pode se tornar um lugar para o pensamento, é porque não há lugar exclusivo para ele - Foucault havia nos mostrado o pensamento arredio a toda e qualquer assinalação topográfica. Essa equivalência dos lugares, essa igualdade de estatuto das vozes, dos modos de fazer e de dizer, encontra-se posta em prática aqui nessa entrevista. Eis aí o método da igualdade, noção que ressoa sem dúvida o aspecto jacotista de seu pensamento. "O pensamento está em trabalho por tudo". Há, no entanto, uma diferença não desprezível entre esses dois volumes. Ao passo que Et tant pis pour les gens fatigués se constitui como um importante instrumento de trabalho para a compreensão da trajetória intelectual de seu autor (na medida em que permite cruzar sua leitura e a publicação de seus livros com entrevistas que tornam possível compreender não apenas a recepção de seu trabalho, mas também o que esteve em jogo no momento em que vieram a público), La méthode de l'égalité apresenta a história dessa trajetória segundo seu próprio autor. A sobreposição da leitura desses dois livros pode ser bastante útil para o historiador. A indistinção de seus estatutos pode ser um problema.

La méthode de l'égalité é dividido em quatro blocos de entrevistas. No primeiro deles, "Gêneses" (RANCIÈRE 2012, p. 13-87), Rancière relembra sua origem familiar, os anos de sua educação fundamental, o percurso que o conduziu ao ingresso na prestigiosa École Normale Supérieure (ENS) e à filosofia, suas ligações com o Partido Comunista no início dos anos 1960, sua militância na Esquerda Proletária, sua entrada no departamento de filosofia da Universidade de Paris VIII (criada no contexto das lutas libertárias de maio de 1968) e a criação do Coletivo-Revista Revoltas Lógicas, em meados dos anos 1970. 
Foi na ENS que se produziu, como se sabe, um encontro intelectual importante, aquele com Louis Althusser e com seu projeto de combate da ciência contra a ideologia. É no final de 1961 que Althusser inicia seu famoso seminário sobre Marx. Nessa época, Rancière preparava uma monografia sobre a ideia de crítica no jovem Marx, inspirado pela interpretação de Jean-Yves Calvez. É sob a influência de Althusser que o objetivo desse projeto se transforma naquele de mostrar a existência de um "corte epistemológico" entre o "jovem" e o "verdadeiro" Marx. É a partir daí que esse trabalho é inscrito no plano do seminário althusseriano sobre O capital, de 1964, que pretendia extrair a racionalidade filosófica que se encontrava em "estado bruto" nessa obra e elaborá-la teoricamente. É interessante descobrir que esse e outros textos não estavam inicialmente destinados a se transformarem em livro. O texto de Rancière, por exemplo, foi confiado a Robert Linhart para se tornar uma apostila voltada à formação teórica de militantes. A decisão de publicá-lo (sem revisão, correção e na forma oral) no Lire le capital foi exclusiva de Althusser e se inscrevia em uma estratégia política a qual Rancière não se vinculava. A partir daí, Rancière relembra todos os problemas ligados à reedição desse livro e de como foi conduzido a romper com o althusserianismo.

Essa ruptura não foi indiferente aos acontecimentos de maio de 1968. Em Althusser, havia a compreensão de que a prática social é produtora de toda uma série de ilusões que eventualmente se tornam objeto de reivindicações ou que aparecem até mesmo no marxismo espontâneo de certos militantes. Para 228 ele, tudo isso não era senão ideologia; caberia à ciência corrigi-la, retificá-la. Nesse sentido, o althusserianismo foi, de certa forma, um mecanismo de poder e de centralização teórica, visto que essa posição se confrontava diretamente com a diversidade de tendências e a pluralidade de interrogações que então existiam e que ficavam reduzidas à ideologia. No entanto, as reivindicações que brotaram em 1968 eram, a partir desse ponto de vista, exclusivamente de "ordem ideológica" e "iam totalmente de encontro ao marxismo que se havia ao mesmo tempo aprendido e ensinado" (RANCIÈRE 2012, p. 37). Essa compreensão althusseriana implicava, ao mesmo tempo, um corte, uma partilha no mundo entre aqueles que possuíam e não possuíam a palavra da ciência, entre sujeitos aptos a ela (neste caso, os intelectuais e os dirigentes do Partido Comunista) e aqueles que apenas poderiam tomar parte nela como objeto. 0 althusserianismo dizia pouco sobre a teoria de Marx e muito sobre a situação então do marxismo. ${ }^{1}$ Maio de 68 marca o momento de um encontro inesperado entre estudantes e operários e produz, dessa forma, um curto-circuito nessa partilha ao mostrar que havia uma considerável distância entre o marxismo de escola e a realidade do mundo operário. Essa ruptura e esse encontro marcaram o devir filosófico rancieriano.

A reorientação do trabalho de Rancière, a partir de 1972, é um efeito desse encontro. É a partir de então que ele inicia, ainda sem um objetivo definido, suas

\footnotetext{
${ }^{1}$ Assinalemos de passagem que La leçon d'Althusser, originalmente publicada em 1974, acaba de ser reeditada a partir do texto original. Ela recebeu, no entanto, um novo prefácio e notas explicativas que ajudam o leitor a se situar em relação ao contexto de sua publicação (RANCIÈRE 2012).
} 
pesquisas nos arquivos operários, justamente com essa ideia de que era preciso encontrá-los em sua própria história. Não devemos nos esquecer de que é nessa mesma época que Michel Foucault organiza o Grupo de Informações sobre as Prisões (GIP). O GIP não criticava apenas o princípio de falar por alguém, a noção de uma consciência ou voz autorizada que tomava a palavra e a fala no lugar de alguém. Ele punha em cheque a própria partilha que dividia a legitimidade dos discursos sobre as prisões, segundo o lugar de sua proveniência. Os prisioneiros possuíam uma teoria das prisões que era absolutamente equivalente às teorias sancionadas ou que os juristas delas possuíam. Daí se atribuía um novo papel para o intelectual: não mais ser a consciência dos movimentos sociais, mas dar voz ao outro, fazer circular esses saberes emudecidos e desqualificados. Essa reorientação do trabalho de Rancière se faz nesse contexto de transformação do estatuto desses saberes e não foi indiferente a ele. São as pesquisas iniciadas nesse período que o conduzem À noite dos proletários (originalmente apresentada como uma tese de doutorado), um livro que não apenas destrói os limites que separam os discursos histórico e filosófico, mas que questiona o modo como os historiadores articulam em uma intriga os acontecimentos e a ordem cronológica, e a maneira como os filósofos concebem o que é o texto filosófico.

O segundo bloco de questões denomina-se "Linhas" (RANCIÈRE 2012, p. 89-166). Trata-se de uma preparação pelos caminhos que conduzem ao seu "edifício filosófico". Rancière evita falar em linhas de filiação de seu pensamento. Há, antes, encontros que o marcaram e que em determinados momentos foram decisivos em sua trajetória. O interessante é que, nessa descrição, Rancière deixa implícito de que aponta nesses encontros apenas aquilo que deles reteve. $\mathrm{Na}$ época de estudante, Sartre e o afastamento "em relação às explicações psicológicas e sociológicas". Em seguida, Althusser e o modo como questionava certa concepção de história por meio da "ideia da multiplicidade dos tempos" (que será fundamental, como sabemos, em A noite dos proletários [1988] e no modo como praticará a história e criticará a historiografia dos Annales). Depois, Foucault e a reviravolta do que constitui o próprio problema da filosofia: não mais o que é pensar, mas o que faz com que tal coisa seja pensável, o que consequentemente o levava a uma nova maneira de articular pensamento e prática.

A essas referências que poderíamos chamar de formativas, há outras que, segundo Rancière, intervieram em momentos precisos de seu trabalho. A reflexão schilleriana sobre a "transformação das formas da experiência sensível"; a crítica kantiana sobre as condições de possibilidade do conhecimento (revisitada, sem dúvida, por Foucault, tal como Rancière o afirma textualmente em O desentendimento [1996]); a compreensão hegeliana de que o pensamento não apenas não se separa, mas concomitantemente se transforma com seus objetos; a reflexão marxista sobre a divisão, de que o que se supõe dado já se encontra em "uma divisão de dados". A essas dívidas, Rancière acrescenta um conjunto de outras que são propriamente extra-filosóficas. Com Flaubert, Conrad e Woolf, ele aprendeu a reconhecer o que chama de "micro-acontecimentos": transformações na paisagem do sensível; primordialmente, no que é pensável, perceptível. Essa dívida literária o marcou no modo como trabalhou com os 
arquivos operários e não apenas em sua escrita da história. Dívidas que nos mostram que o trabalho de Rancière não se filia a uma escola, mas que está atravessado por toda uma série de múltiplas referências não necessariamente convergentes entre si.

Esse segundo bloco dedica-se ainda a explorar a "sistematicidade antissistemática" da filosofia rancieriana. Ela é sistemática, no sentido de que há um conjunto de preocupações recorrentes em seu trabalho. Ela é assistemática no sentido em que recusa a própria formulação de uma teoria global que se desdobraria em diferentes domínios. A heterorracionalidade em marcha em diferentes práticas não se unifica em uma teoria global. Em seguida, trata da importância das figuras espaciais em seu pensamento. Por meio delas, critica-se a noção marxista de ideologia e busca-se pensar o modo de distribuição, de disposição dos corpos em sociedade segundo as capacidades que lhe são atribuídas. A noção de espaço liga-se aqui àquela de tempo. É nessa ligação que a noção de "cena", fundamental em Rancière de um ponto de vista metodológico e teórico, tornase importante. Em detrimento da noção de origem (do pensamento, da política etc.), trata-se de pensar a configuração de cenas a partir das quais certas distribuições se operam. É a partir daí que ele retomou uma crítica do tempo como princípio de interdição, espacializando essa noção. Sua crítica ao modo como se compreendeu a disciplina como tecnologia de poder (no final dos anos 1970), sua análise dos discursos do fim (a partir do final dos anos 1980) e sua crítica à noção de identidade se fizeram a partir daí.

2.30 Por isso, Rancière caracteriza seu trabalho como uma poética ou teoria geral das multiplicidades. Não se trata de ontologizar a diferença e a singularidade, mas de pensar que as cenas políticas se configuram a partir de uma não-concordância entre o excesso de nomes e a multiplicidade de corpos. Para ele, a literatura se constituiu precisamente nesse intervalo, buscando tratar esse excesso e essa não-concordância: nesse traço reside sua contradição fundadora. A constituição das identidades deve ser pensada em relação às multiplicidades (de lugares, de pertencimentos, de experiências possíveis) e não remetida ao enraizamento em um lugar e em uma cultura. É aí que se situa a importância da noção de "palavra" (muda, errante, operária), capaz de qualificar um acontecimento (por meio da auto-declaração), da subjetivação nas palavras, i.e., a capacidade de se apropriar de uma palavra que permite frasear de outro modo a experiência. Um acontecimento, assim, não é uma ruptura em uma cadeia causal (o que pressupõe uma lógica hierárquica), mas uma "alteração", "uma reconfiguração de um campo de possíveis" (RANCIÈRE 2012, p. 117; 119). ${ }^{2}$ Essa discussão leva àquela sobre o estatuto da estética em seu pensamento, à definição da noção de revolução estética, à relação entre a língua filosófica e a língua ordinária em sua escrita, que toma distância do comentário filosófico tradicional, que prefere falar em "processos de conceitualização" ou "de constituição de uma paisagem

\footnotetext{
2 Essa noção de acontecimento distancia-se daquelas de um Foucault ou de um Deleuze. A questão que seria interessante considerar é como Rancière a articula com a história ou, dito de outro modo, como a explicitação dessa noção permite acessar sua teoria da história.
} 
conceitual" ao invés de simplesmente em conceitos, e que se afasta da ideia da filosofia como "caixa de ferramentas".

O terceiro bloco de perguntas intitula-se "Limiares" (RANCIÈRE 2012, p. 167253). Ele se inicia com a discussão da ideia de crítica em seu trabalho. É explícito seu afastamento da teoria crítica ou da lógica tradicional da desmistificação ("lógica da autoridade"), segundo a qual há sempre aqueles que, em função de seu conhecimento, sabem o que se passa em determinado momento, e que legitimamente se voltam para aqueles que acreditam saber o que se passa com o intuito de lhes mostrar ou que nada se passa ou que aquilo que ocorre é coisa diferente do que se acredita (vemos hoje na ecologia política a última atualização desse discurso). Suas crônicas dos tempos consensuais interferem na cena contemporânea a partir de outra ideia de crítica, como "desconstrução da autoridade": não revelar aos ignorantes a verdade escamoteada em um conflito, mas mostrar no coração de sua própria cena a confrontação de dois mundos sensíveis nos quais não há verdade das coisas (um inteligível necessário sob o sensível irracional) - encontramos aí uma definição mínima de política: manifestação brutal do conflito entre dois regimes de identificação do sensível. Trata-se de pensar em termos dissensuais, de que é a própria articulação entre sentido e sensível que está em jogo em uma cena. E é aí que se situam suas análises sobre a ordem consensual. Mas é também aí que poderíamos situar sua recusa e crítica às posições de autoridade de uma sociologia da distinção de um Bourdieu, ao modo como a história cultural e das mentalidades analisaram a palavra herética e ao revisionismo historiográfico.

Rancière não é despreocupado com os efeitos dessa crítica. É pelo fato de que ela intervém em nossa atualidade, que se preocupa com seus efeitos. Isso é particularmente sensível em relação ao campo artístico: críticos, historiadores da arte, curadores e até mesmo artistas se inspiram em seu trabalho. "Partilha do sensível" tornou-se uma noção repetida em todas as línguas (no final do livro, ele aborda essa questão). E não se trata de um tipo de conceito que se possa facilmente "aplicar". E esse é um traço do procedimento de Rancière: seu modo de trabalhar, suas descrições empíricas, o emprego e a construção de conceitos encontram-se todos imbricados em uma mesma operação inseparável de escrita (a noção historiográfica de "tratamento das fontes" é totalmente estranha ao seu modo de trabalhar). Daí certa dificuldade intrínseca a essa obra que não quer fornecer uma teoria ou um quadro de conceitos "aplicáveis" em diferentes domínios. Por isso, esse livro não pode ser pensado desconectado dessa preocupação. Algumas das questões propostas pelos entrevistadores remetem a críticas que se fizeram ou a objeções que poderiam ser feitas ao seu trabalho, ao modo como foi recebido ou a interpretações de que ele poderia ser objeto. Certas questões buscam precisar noções (emancipação, igualdade/ desigualdade, subjetivação, simbolização, desidentificação, sobre a suposta raridade da política, lugar do social), figuras (cultura popular) e passagens difíceis de serem totalmente compreendidas. Muitas outras dizem respeito a possíveis aproximações que podem ser feitas entre suas noções e aquelas de diferentes autores e a de seu pensamento com o trabalho de personagens 
importantes na paisagem filosófica contemporânea, particularmente com os de Foucault e Deleuze. Foucault, aliás, de longe, o autor mais citado ao longo do livro - sem dúvida em função da insistência dos entrevistadores para que Rancière se posicionasse sobre certas noções políticas e filosóficas de seu antigo professor.

Nessa terceira parte do livro, os entrevistadores introduzem ainda a tão esperada questão sobre sua "concepção de história a partir do problema do novo" (RANCIÈRE 2012, p. 223). O problema é que colam essa pergunta a uma explicação sobre as metamorfoses dos regimes de identificação da arte (que ele havia estabelecido n'A partilha do sensível). Isso o conduz muito mais a uma explicitação sobre os elementos que permitem apontar uma mudança nesses regimes do que a uma explicitação de sua concepção de história. Os três "regimes de historicidade" da arte (sem relação com os regimes de François Hartog, que curiosamente desconhece o trabalho de Rancière) não devem ser confundidos com "três idades da humanidade". Não há entre eles um "corte radical". Da mesma forma, essa mudança é lenta, visto que uma nova lógica de identificação da arte não se impõe imediatamente. A estética é, nesse sentido, um domínio distinto em relação àquele da política, onde a novidade se "impõe em um ritmo acelerado" (RANCIÈRE 2012, p. 228). O acontecimento político é vertiginoso. Essa transformação de regime não é consciente ou explicitamente anunciada: pode-se mostrar como o sentido da palavra literatura se transforma no final do século XVIII, mas essa mudança não é então conceitualizada e nem tampouco declarada. Isso porque esse tipo de novidade seguidamente advém de

232 uma "declaração retrospectiva". Assim, se se pode reconhecer historicamente a emergência desses regimes, que podem mesmo coexistir, eles não se confundem com uma época histórica.

Os historiadores, sem dúvida, lamentarão o fato de os entrevistadores não terem explorado toda a série de questões suscitadas pela publicação de um livro como Les noms de I'histoire (1992). Seria interessante conhecer o contexto de sua elaboração e o interesse de Rancière em escrever essa inaudita arqueologia da Nova História - pouquíssimo lida e comentada pelos historiadores que se mostram, em geral, mais receptíveis aos manuais escolares. Isso decorre do próprio fato de como os entrevistadores conceberam-no. Ao contrário, por exemplo, dos livros de entrevista feitos por Didier Eribon com Claude Lévi-Strauss e com Georges Dumézil, não há uma preocupação com a história da elaboração dos problemas e do pensamento de Rancière. Só há gênese na parte inicial do livro.

A quarta e última parte de La méthode de l'égalité intitula-se "Presentes" (RANCIÈRE 2012, p. 255-321). Rancière caracteriza seu trabalho como uma "cartografia dos possíveis". Possível não é o que se opõe ao real, pois real é o que é possível. Se há aí bergsonismo, ele é inconfesso. O possível não é algo que se atualizará. Os possíveis de que ele fala já se efetuaram, foram atualizados. Trata-se, portanto, de "uma maneira de pensar o que é" (RANCIÈRE 2012, p. 256), de pensar o estatuto de uma atualidade. Ele se opõe, assim, ao necessário, que é o conjunto de encadeamentos que precedem o que é, fazendo com que o real não possa ser diferente do que ele é. Trata-se de recolocar o 
possível no real e subtraí-lo do necessário. O modo como ele pensa a política e como a articula com a história pode ser entrevisto a partir daí, de descrições cartográficas, topográficas, cenográficas, visto que a importância na descrição de cenas de manifestação do sensível em seu trabalho nos leva a enxergá-lo, antes de tudo, como um novo cenógrafo da política. Pois não se trata de pensar como, por meio de conexões precedentes e de articulações necessárias, um tempo substitui outro, mas na coexistência de diferentes modos de presença, quer dizer, de presentes em um presente, de diferentes temporalidades em um mesmo tempo - poderíamos lembrar aqui de como a anacronia desempenha um papel importante em suas cartografias e cenografias políticas.

Assim, a revolução, o acontecimento por excelência, não deve ser entendida como a culminância temporal necessária de uma ordem causal. Deve-se evitar falar em "a" revolução em proveito do plural "revoluções". Uma revolução é "o momento em que toda uma ordem do visível, do pensável, do possível se encontra brutalmente demitida e substituída" (RANCIÈRE 2012, p. 269). É a "interrupção de toda uma ordem simbólica dada": torna-se possível uma série de coisas até então consideradas impensáveis, impossíveis, e uma nova figura do povo, até então sem lugar e sem parte nessa ordem, entra em cena. Ela não é a realização de uma necessidade histórica, a tomada do poder e a transformação da ordem econômica que determinava a configuração da ordem social e política. Ela é antes a possibilidade de construção de outro "mundo sensível e pensável", de um comum outro. É nesse sentido que, para ele, a Primavera Árabe, mas também toda uma série de acontecimentos passados pode ser qualificada como revolução, visto que esse conceito não remete à ideia de um ponto de intersecção entre épocas ou se mede em função de suas consequências futuras. Se Rancière, portanto, não define um papel para o intelectual atualmente, de sua parte, esforça-se para que o espaço de pensamento sobre as possibilidades de emancipação permaneçam abertas e mesmo desejáveis.

Jeanpierre e Zabunyan, a partir daí, conduzem-no a pensar como seus trabalhos estiveram quase sempre ligados à emergência de problemas específicos. Aqui aparece a discussão sobre as noções de polícia (que não se confunde com o braço armado do Estado), epistemocracia e consenso, com as quais buscou qualificar nossa democracia atual, ou melhor, o modo como se construiu nossa atual configuração do sensível, como um mundo da necessidade onde não há mais possível e no qual não mais se permite construir outras formas do comum. Todas essas questões desenvolvidas em $O$ desentendimento (1996) podem aqui ser situadas em relação a conjunturas específicas de sua elaboração. É nessa última parte do livro, mais do que em outras, que Rancière conecta as reflexões que se encontram em seus livros com problemas atuais: polícia global, política mundial, novas formas de dominação, destruição dos empregos e do tecido social, ONGs, reafirmação da importância dos movimentos sociais locais na construção de cenas políticas universalizáveis, imigração, os sem-documentos, ecologia política, circulação da informação (e a importância dos artistas do Oriente Médio, por ex., que nos fazem ver coisas sobre essa região que não víamos), arte contemporânea, fait divers, invenção de artes de viver em meio à precariedade, futuro do socialismo, economia política. 
O corpus rancieriano cresceu sobremaneira nos últimos anos. Não nos referimos aos inúmeros livros oriundos de pesquisas originais publicados há pouco, que mostram a vitalidade de um pensamento que adquiriu recentemente importante reconhecimento. É perceptível sua preocupação em reunir em livro textos esparsos. Les écarts du cinéma (2011) é um exemplo. Moments politiques (2009), que reúne suas intervenções na opinião pública entre 1977 e 2009, é outro. Reeditar outros há tempos desaparecidos das livrarias, eis aí La parole ouvrière (2007), essa coletânea de escritos proletários do século XIX. Seus "escritos" vão assim sendo inscritos, reinscritos nesse corpus, desnaturados, por assim dizer, dos lugares e contextos originais de sua publicação. O mesmo pode se afirmar sobre seus inúmeros "ditos" reunidos no volume de entrevistas de 2009. Sem dúvida, esse livro-entrevista também se inscreve nesse corpus. Mas, ao contrário das outras publicações, ele não se situa apenas ao lado de todos esses outros volumes da biblioteca rancieriana. Ele intervém na própria disposição desse corpus, visto que Ihe dá, de certa forma, um sentido.

A publicação desse livro é indissociável não apenas ao crescente interesse pelo trabalho de Rancière, mas ao surgimento dos primeiros debates e estudos sobre sua obra. Trata-se, portanto, de um livro inseparável de uma preocupação com os efeitos de sua obra. E é talvez a esse público - o de seus leitores interessados - que ela esteja voltada. Esse mestre ignorante, sem escola e sem discípulos, que há alguns anos retirou-se do púlpito do magistério universitário, dirige-se aqui diretamente aos seus leitores sobre questões suscitadas pela sua leitura. É sobre o modo como ela é lida, sobre certas incompreensões, sobre precisões necessárias ou conflitos de interpretação por ela gerados que esse livro ressoa. Trata-se, antes de tudo, de um diálogo com seus leitores.

\section{Referências bibliográficas}

RANCIÈRE, Jacques. A noite dos proletários: arquivos do sonho operário. Trad. Marilda Pereira. São Paulo: Cia. das Letras, 1988.

. A partilha do sensível: estética e política. Trad. Mônica Costa Netto. São Paulo: EXO experimental org.; ed. 34, 2005.

Chroniques des temps consensuels. Paris: Seuil, 2005.

. Et tant pis pour les gens fatigués. Entretiens. Paris: Amsterdam, 2009.

. La leçon d'Althusser. Paris: La Fabrique, 2012.

La parole ouvrière. Textes présentés para Jacques Rancière et Alain Faure. Paris: La Fabrique, 2007.

Les écarts du cinéma. Paris: La Fabrique, 2011.

. Les noms de I'histoire: essai de poétique du savoir. Paris: Seuil, 1992.

Moments politiques: interventions 1977-2009. Paris: La Fabrique, 2009.

O desentendimento: filosofia e política. Trad. Ângela Leite Lopes. São Paulo: Editora 34, 1996. 